\title{
Ultrasound Guidance Versus Peripheral Neurostimulation for Brachial Plexus Block Anesthesia with Axillary Approach and Multiple Injection Technique
}

\author{
Alexandra Lazar, János Szederjesi*, Elena Iftenie, Leonard Azamfirei \\ University of Medicine and Pharmacy Tîrgu Mureș, Romania
}

\begin{abstract}
Introduction: There are several approaches for brachial plexus anesthesia: supraclavicular, infraclavicular, interscalenic and axillary. Out of these, the axillary approach is considered to be the safest because of the low risk of lesioning the adjacent structures, low risk of phrenic nerve blockade or of producing an iatrogenic pneumothorax. The block can be performed by one single injection at the site, by two injections or by several injection, among each nerve of the plexus. Ultrasound was introduced in regional anesthesia since 1978, being used initially as an auxiliary method to peripheral neurostimulator. Objectives: The evaluation of ultrasound efficiency as an auxiliary method for brachial plexus block performance, in terms of success rate, vascular punctures. The influence of obesity on performing time, total duration of the block, and success rate of brachial plexus block. Material and method: Prospective, randomized study which enrolled adult patients, scheduled for surgical emergency or elective surgical intervention on upper limb with brachial plexus block by axillary approach, using either the peripheral nerve stimulation or the ultrasound guidance. Results: We enrolled 160 patients, grouped in two sets- the ultrasound group= 82 patients (US) the neurostimulation group $=78$ patients (NS). Vascular punctures were statistically significant different $p=0,04$. The success rate was not influenced by the obesity. Conclusions: Ultrasound guidance makes axillary brachial plexus block safer, we can recommend ultrasound guidance as routine for axillary brachial plexus block. The obese patient can beneficiate by both methods of brachial plexus blockage.
\end{abstract}

Keywords: brachial plexus block, ultrasound, neurostimulation, obesity, vascular punctures

Received 4 June 2017 / Accepted 18 July 2017

\section{Introduction}

Anesthesia and analgesia methods for hand surgery consists of general and regional procedures. Regional anesthesia is getting ahead for hand surgery. This is due to the known advantages of regional anesthesia compared to general anesthesia. Among these advantages, we point out the awake state of the patient, the fact that it does not imply major modifications on the major body systems and organs: lungs, heart, and vascular system. Postoperatively, this mode of anesthesia offers up to 8 hours analgesia [1].

There are several approaches for brachial plexus anesthesia: supraclavicular, infraclavicular, interscalenic and axillary. Out of these, the axillary approach is considered to be the safest because of the low risk of producing lesions to the adjacent structures, low risk of phrenic nerve blockade, and of producing an iatrogenic pneumothorax. Although superior among the other approaches of brachial plexus, even with this procedure, the risk of inadvertent intravascular injection of the local anesthetics persists [2].

For performing the axillary brachial block by axillary approach, a few technique possibilities exist. The block can be performed by single injection at the site, by two injections or by several injections, for each nerve of the plexus. The last one is considered to be the safest method, ensuring a high success rate. A study of Casati et al. showed a failure

* Correspondence to: János Szederjes

E-mail: yangzi37@gmail.com rate of $3 \%$ when using ultrasound and multiple injection technique, for this regional procedure [3].

At the beginning, for brachial plexus blockade the techniques, which implied paresthesia, or the trans-arterial technique. When the peripheral neurostimulator was introduced in 1912 by Perthes, the nerves could be properly and precise localized, most of the disadvantages of the above-mentioned methods being eliminated. This became the preferred method for nerve localization, until the ultrasound was introduced as an auxiliary method to brachial plexus block [4].

The possibility of direct visualization of the anatomic structures, the vessels and the nerves as well as the needles and the anesthetic spreading during the technique, increased the blocks success rate to up to $99 \%[5,6]$.

Ultrasound was introduced in regional anesthesia in 1978 , being used initially as an auxiliary method to peripheral neurostimulation. However, accidents such as vascular punctures and intravascular anesthetic administration continued to be present, this being the main reason that made needle visualization as well as the anesthetic spreading, to be a must in regional techniques. The industry developed needles with special properties, such as a different angle in faceting, which helps for a better reflection of the ultrasounds. These proprieties increased their visibility under ultrasound. Also, the ultrasound machines were improved to better localize the nervous structures. [7] 


\section{Objectives}

The evaluation of ultrasound efficiency as an auxiliary method for brachial plexus block, in terms of success rate, vascular punctures.

The influence of obesity on performing time, total duration of the block, and success rate of brachial plexus block.

\section{Material and method}

The prospective, randomized study was conducted in the Emergency Clinical County Hospital Tîrgu-Mureș. The study was approved by the Ethics Committee of the Emergency Clinical County Hospital, (No.2987/2013) and by the Ethics Committee of the University of Medicine and Pharmacy of Tîrgu Mureș (No.40/2013).

The patients were recruited by signing an informed consent form before performing the technique. The study enrolled adult patients, scheduled for emergency surgery or elective surgery on upper limb. The anesthetic procedure was the brachial plexus block with axillary approach, by multiple injections technique, using either the peripheral nerve stimulation or the ultrasound guidance. The inclusion of the patients was randomized, one patient had the brachial plexus block performed with the help of the peripheral neurostimulation, and the next one had the brachial plexus block performed with ultrasound guidance.

The materials used for anesthesia were the following:

- Peripheral nerve stimulator -B Braun (BBraun, Germany) - Stimuplex HNS 12

- Ultrasound -G\&E Logique (General Electric, Chicago, Il, USA) - 9mm linear probe

- Needles 50mm STIMUPLEX Ultra Insulated Needles with $30^{\circ}$ Bevel B Braun (BBraun, Germany)

- Anesthetic substances were Ropivacaine- $10 \mathrm{mg} / \mathrm{ml}-($ Fresenius Kabi Pharma, Portugalia) and Lidocaine 1\%, (Infomed Fluids, Bucharest, Romania), ana partes aequales $0.5 \%$ concentration, the anesthetic volume administered was between $8-10 \mathrm{ml} /$ nervous structure.

We anesthetized the following nerves: musculocutaneous, median, ulnar and radial.

After informing and obtaining the written consent, the patient was positioned in supine position, with the arm of the injured limb abducted at 90 degree.

After inserting a peripheral venous cannula and standard monitoring the vital signs (noninvasive blood pressure, EKG, peripheral oxygen saturation) the exact spot of the puncture was established by identifying the axillary artery, in the axilla. Before the start of the anesthetic procedure, an amount of 1-2 $\mathrm{ml}$ of local anesthetic was administered subcutaneously for subcutaneous brachial nerve anesthesia.

The anesthetic procedure was performed either by peripheral neurostimulation or by ultrasound guidance.

\section{By peripheral neurostimulation}

A $50 \mathrm{~mm}$ stimulating needle was initially introduced anterior and superior to the axillary artery for musculocu- taneous and median nerve localization, then the needle was oriented inferiorly to the artery for the ulnar nerve and posteriorly and inferior for radial nerve localization. The amplitude of the electric stimulus was initially set at $1,2 \mathrm{~mA}$, being reduced as we approached the nerve. The anesthetic administration was made at an amplitude lower than $0.5 \mathrm{~mA}$, but higher than $0.2 \mathrm{~mA}$.

\section{By ultrasound guidance}

The axillary artery was located by direct visualization along with the nerves, which are located around the artery. For anesthetic injection, $50 \mathrm{~mm}$ needles with increased ultrasound visibility were used.

The anesthetic injection method was that of multiple injections, around the each nerve.

A complete motor and sensitive brachial block was considered a successful anesthesia.

The processed data were:

1. The performing time of the anesthesia - measured from the moment of the puncture until the moment of needle extraction.

2. Vascular incidents - accidental vascular punctures encountered during the anesthetic procedure

3. Body mass index and success rate, vascular punctures.

The data were processed with the program GraphPad Prism 7.0. A value of 0.05 alpha $(\alpha=0.05)$ was established, and a confidence interval of $95 \%$. The normality of the series was established by D'Agostino test. For series comparison, the following statistic tests were used: Man Whitney for non-parametric data and $t$ student test for unpaired data, when a normal distribution was present. The difference between proportions was tested by Chi test. In order to analyze the variables, we deemed necessary to use logistic regression models.

\section{Results}

We enrolled 160 patients, two groups. The ultrasound group comprised of 82 (US group) patients and the neurostimulation group had 78 patients (NS group).

When the groups were compared as to performing time, no significant statistic difference was noted between the two groups, $p=0.74$. The mean performing time in the NS group was $12.27 \pm 6.96$ minutes, very similar with the US group, where the mean performing time was of $12.26 \pm$ 6.21 (Figure 1).

For the accidental vascular punctures the US group was advantaged by a significantly lower rate $(\mathrm{p}=0.04)$ (Figure 2$)$.

Obesity was defined as a value of BMI over 25 . We enrolled a total of $88(55.7 \%)$ patients with an BMI> 25 out of 158 , for two patients from the US group the necessary data to calculate BMI were not obtained. Figure 3 shows the number of each category of patients, in terms of BMI, from the two studied groups.

There were no statistically significant differences regarding the number of the obese patients or the mean body mass index between the studied groups. 


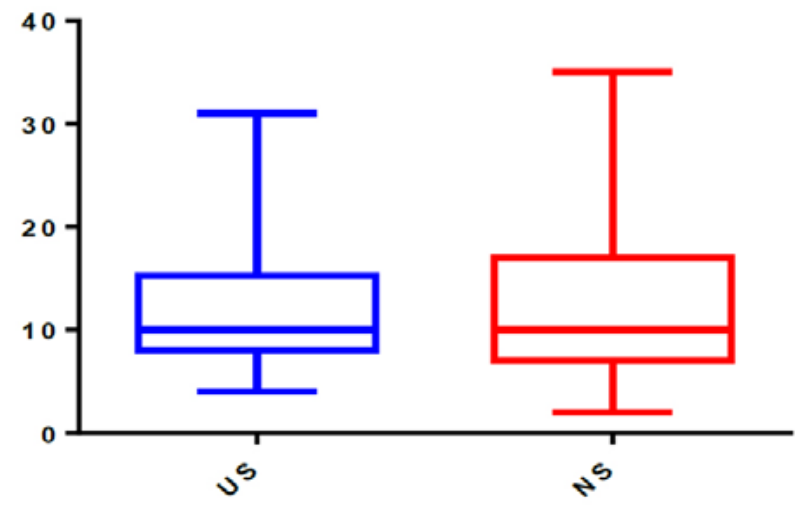

Fig. 1. The performing time of the brachial plexus block by the studied methods.

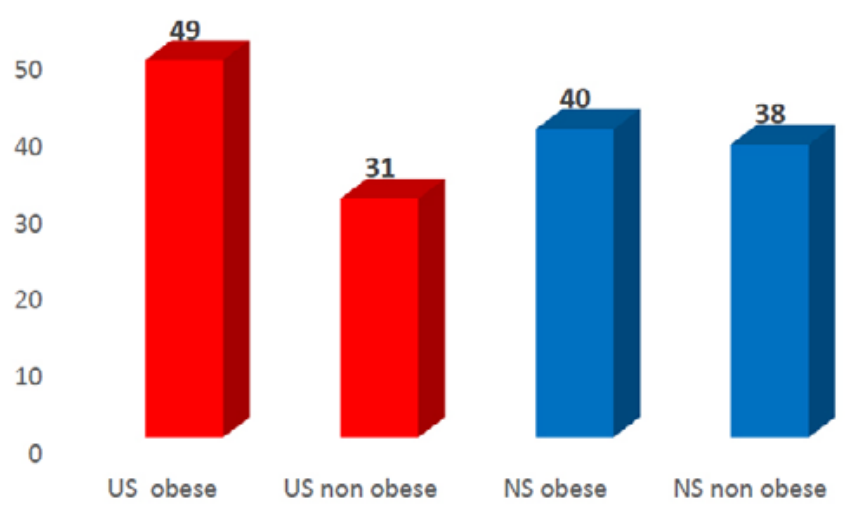

Fig. 3. Obese patients in the two groups.

The success rate of the block was not influenced by the obesity. Table I represents Pearson correlation results when the groups were compared in terms of success rate and obesity.

Table I. Relationship between BMI and the success rate of the block

\begin{tabular}{lcccc}
\hline $\begin{array}{l}\text { p-values } \\
\text { Pearson correlation }\end{array}$ & & $\begin{array}{c}\text { Partial } \\
\text { Block non } \\
\text { obese - NS }\end{array}$ & $\begin{array}{c}\text { Partial } \\
\text { Block non } \\
\text { obese US }\end{array}$ \\
\hline Partial Block obese US & & 0.21 & 0.61 & 0.69 \\
Partial Block obese NS & 0.21 & & 0.61 & 0.96 \\
Partial Block non obese - NS & 0.61 & 0.61 & & 0.96 \\
Partial Block non obese US & 0.69 & 0.96 & 0.96 & \\
\hline
\end{tabular}

Table II. Correlation between vascular punctures and the obese vs non obese patients from the two groups.

\begin{tabular}{lcccc}
\hline $\begin{array}{l}\text { p- values } \\
\text { Pearson correlation }\end{array}$ & $\begin{array}{c}\text { Vascular } \\
\text { punctures- } \\
\text { obese NS }\end{array}$ & $\begin{array}{c}\text { Vascular } \\
\text { punctures } \\
\text { obese US }\end{array}$ & $\begin{array}{c}\text { Vascular } \\
\text { punctures } \\
\text { non obese } \\
\text { NS }\end{array}$ & $\begin{array}{c}\text { Vascular } \\
\text { punctures } \\
\text { non obese } \\
\text { US }\end{array}$ \\
\hline $\begin{array}{l}\text { Vascular punctures- } \\
\text { obese NS }\end{array}$ & & 0.43 & 0.09 & 0.35 \\
$\begin{array}{l}\text { Vascular punctures } \\
\text { obese US }\end{array}$ & 0.43 & & 0.14 & 0.37 \\
$\begin{array}{l}\text { Vascular punctures } \\
\text { non obese NS }\end{array}$ & 0.09 & 0.14 & & 0.33 \\
$\begin{array}{l}\text { Vascular punctures } \\
\text { non obese US }\end{array}$ & 0.35 & 0.37 & 0.33 & \\
\hline
\end{tabular}

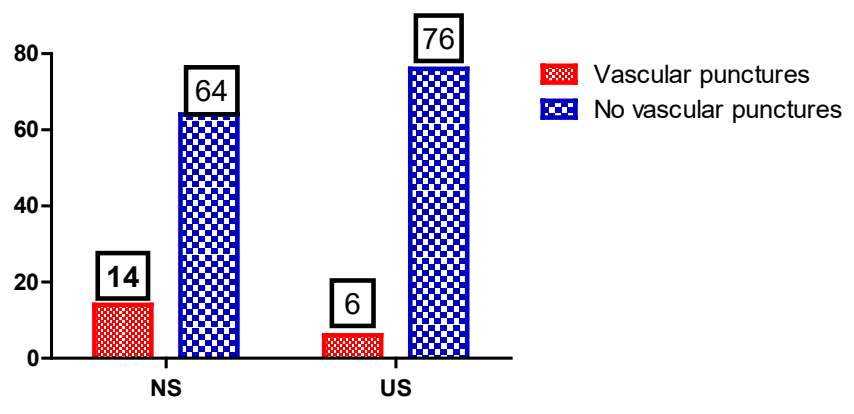

Fig. 2. Vascular punctures in the US group compared with NS group

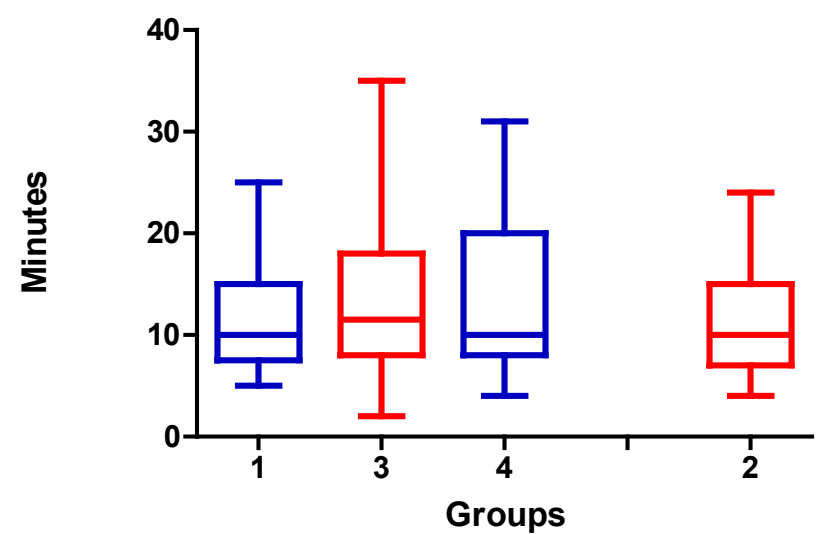

Fig. 4. Performing time in the studied groups 1 - Obese patients US; 2- Obese patients NS; 3- Non obese patients NS; 4- Non obese patients NS

Obesity did not influence significantly the number of vascular punctures. There was no significant statistic difference between the subgroups; $p$ values of the statistical correlation are listed in table II.

The performing time of the procedure when the obese were compared with non-obese in the two formed subgroups, showed a positive significant correlation between the times needed to perform the procedure in non-obese patients from the US group and the obese patients from the US group. Table III presents the detailed correlations.

The time needed to perform the procedure for the different groups is presented in figure 4. Table IV shows the exact time needed to block the brachial plexus in every studied group.

\section{Discussions}

Brachial plexus anesthesia for hand surgery is increasingly used either to complete general anesthesia or as a single technique. The classical approach for nerve localization is peripheral neurostimulation, but in the last two and a half decades, ultrasound guidance is increasingly used as an auxiliary method in regional anesthesia. This is because trough peripheral neurostimulation the direct visualization of nervous and vascular structures is not possible. This aspect offers a higher safety degree during the ultrasound guided procedure. Some may still be reluctant to use the ultrasound because the need of supplementary knowledge. 
Table III. The correlation between the groups in the light of obesity and performing time

\begin{tabular}{lcccc}
\hline p- values & $\begin{array}{c}\text { Performing } \\
\text { time obese } \\
\text { US }\end{array}$ & $\begin{array}{c}\text { Performing } \\
\text { time obese } \\
\text { NS }\end{array}$ & $\begin{array}{c}\text { Performing } \\
\text { time non } \\
\text { obese NS }\end{array}$ & $\begin{array}{c}\text { Performing } \\
\text { time } \\
\text { non obese } \\
\text { US }\end{array}$ \\
\hline $\begin{array}{l}\text { Performing time } \\
\text { obese US }\end{array}$ & 0.19 & 0.04 & 0.42 \\
$\begin{array}{l}\text { Performing time } \\
\text { obese NS }\end{array}$ & 0.19 & & 0.10 & 0.24 \\
$\begin{array}{l}\text { Performing time } \\
\text { non obese NS }\end{array}$ & 0.04 & 0.10 & & 0.18 \\
$\begin{array}{l}\text { Performing time } \\
\text { non } \\
\text { obese US }\end{array}$ & 0.42 & 0.24 & 0.18 & \\
\hline
\end{tabular}

Table IV. Performing time for the studied groups

\begin{tabular}{lcccc}
\hline & $\begin{array}{c}\text { Performing } \\
\text { time obese } \\
\text { US } \\
\text { (minutes) }\end{array}$ & $\begin{array}{c}\text { Performing } \\
\text { time obese } \\
\text { NS } \\
\text { (minutes) }\end{array}$ & $\begin{array}{c}\text { Performing } \\
\text { time non } \\
\text { obese NS } \\
\text { (minutes) }\end{array}$ & $\begin{array}{c}\text { Performing time } \\
\text { non obese US } \\
\text { (minutes) }\end{array}$ \\
\hline Minim & 5.000 & 4.000 & 2.000 & 4.000 \\
Maxim & 25.00 & 24.00 & 35.00 & 31.00 \\
Mean & 11.33 & 11.23 & 13.43 & 13.39 \\
$\begin{array}{l}\text { Standard } \\
\text { deviation }\end{array}$ & 5.051 & 5.881 & 7.722 & 7.260 \\
\hline
\end{tabular}

The execution time is not affected by the method used to perform the block, the values obtained in this respect for the two groups of patients being very close and with no significant difference. Moreover, the literature shows similar results; a study conducted in 2012 obtained similar results when using the ultrasound method for axillary brachial plexus block - 12.2 minutes [8] and another study, again in 2012, presented a performing time of 15.7 minutes [9].

The obtained values in this study, for the performing time, were 12.27 minutes in the US group, value very close to the value reported in the above-mentioned studies, but with a higher specificity due to the larger number of patients that the study enrolled. The obtained value on performing the ultrasound guided brachial plexus block was also close to that obtained when the oldest approach was used, peripheral neurostimulation, this showing that ultrasound guidance is not delaying the procedure.

This study points out the significant advantage that ultrasound guidance brings to the safety of this procedure. In the US group, the number of vascular punctures was significantly lower compared to the NS group. The advantages of the ultrasound guided regional anesthesia is well recognized by specialists around the world, this study reinforcing the statements that the ultrasound guidance reduces significantly the number of vascular punctures [10]. This is what we also obtained, the ultrasound guidance significantly reduced $(p<0.05)$ the number of vascular punctures, making the procedure safest, thus diminishing the risk of intravascular injection of the local anesthetics.

The obese patients are a group of patients with supplementary risks for anesthetic procedures, because the anatomical marks are altered and sometimes it is not that easy to palpate the axillary artery, which is the landmark for the brachial plexus block with axillary approach. When we studied the enrolled patients in this respect, we found no correlations between BMI and the number of vascular punctures. The same results were reported in literature, the conclusion being that the obesity does not influence significantly this regional anesthetic procedure, regardless of the method used to perform the brachial plexus bock. [11].

The literature advises the use of ultrasound guidance for patients with a body mass index above 30 because on those patients, the anatomical marks are harder to locate, but a meta-analysis conducted on the studies which evaluated this aspect, did not graded this recommendation to be representative $[12,13]$. This study is limited by the fact that it considered only this approach of the brachial plexus block, and that it was only conducted on the axillary block.

\section{Conclusion}

Ultrasound guidance makes axillary brachial plexus block safer in terms of incidence of vascular puncture. Therefore, we recommend ultrasound guidance as routine for axillary brachial plexus block.

The obese patient can benefit by both methods of brachial plexus blockage, ultrasound or neurostimulator guided, without any significant risks compared to non-obese patients.

\section{Acknowledgement}

This study is part of the $\mathrm{PhD}$ thesis entitled: Comparative pharmacological studies on the method of sodium channel inhibition by local anesthetics, anticonvulsants and antiaritmics and the use local anesthetic admixtures in brachial plexus block with axillary approach.

\section{Bibliography}

1. Lazar A, Szederjesi J, Copotoiu S.M et al. Combination of Ropivacaine and Lidocaine for long lasting locoregional anaesthesia. Acta Medica Marisiensis- 2014;60(2): 41

2. Ashish R.S, David M S. Axillary Brachial Plexus Block. Anesthesiol Res Pract. 2011: 173796

3. Nowakowski P1, Bieryło A.Ultrasound guided axillary brachial plexus plexus block. Part 1--basic sonoanatomy. Anaesthesiol Intensive Ther. 2015;47(4):409-16

4. Coventry DM, Barker KF, Thomson M Comparison of two neurostimulation techniques for axillary brachial plexus blockade. Br J Anaesth. 2001 ; 86(1):80-3

5. Kapral S, Greher M, Huber G, et al. Ultrasonographic guidance improves the success rate of interscalene brachial plexus blockade. Reg Anest and Pain Med.2008;33(3):253-258

6. Perlas A, Brull R, Chan WWS, et al. Ultrasound guidance improves the success of sciatic nerve block at the popliteal fossa. Reg Anest and Pain Med. 2008;33(3):259-265

7. Kim JH, Chen J, Bennett $\mathrm{H}$ et al. A low approach to interscalene brachial plexus block results in more distal spread of sensory-motor coverage compared to the conventional approach. Anesth Analg. 2011; 112(4):987-9

8. Tran de $\mathrm{QH}$, Pham K, Dugani S, et al: A prospective, randomized comparison between double-, triple-, and quadruple-injection ultrasoundguided axillary brachial plexus block. Reg Anesth Pain Med. 2012; 37: 248-253

9. Bernucci F, Gonzalez AP, Finlayson RJ, et al: A prospective, randomized comparison between perivascular and perineural ultrasound-guided axillary brachial plexus block. Reg Anesth Pain Med. 2012; 37: 473-437.

10. Nowakowski P, Bieryło A. Ultrasound guided axillary brachial plexus 
plexus block. Part 2 - technical issues.. Anaesthesiol Intensive Ther.2015;47(4):417-24.

11. Shaylor R, Saifi F, Davidson E, et al. High Success Rates Using Ultrasound for Neuraxial Block in Obese Patients. Isr Med Assoc J. 2016;18(1):36-9

12. Chin KJ, Perlas A, Chan V, et al. Ultrasound imaging facilitates spinal anesthesia in adults with difficult surface anatomic landmarks. Anesthesiology 2011; 115: 94-101

13. Shaikh F, Brzezinski J, Alexander S, et al. Ultrasound imaging for lumbar punctures and epidural catheterisations: systematic review and metaanalysis. BMJ 2013; 346: 1720 